\title{
Psychological Processes in Language Learning and Teaching: Scoping Review and Future Research Directions
}

\author{
Manna Dey
}

Published online: 25 December 2021.

\begin{abstract}
The field of psycholinguistics has produced many hypotheses which explain how a person speaks and understands the language spoken or written. In the area of language, instruction theories have been employed. In designing language education approaches, several professionals adopt them as their fundamental theories. It is called a method of psycholinguistics. Psycholinguistic method considers learning as an individual cognitive process that takes place within the individual and then moves to the social dimension. There are various ways, such as natural method, whole physical response methods, and suggested contemporary method, which are founded on the theory of the psycholinguist. These methods utilise psychological concepts, such as learning your first or second language (second language learning), learning a language (linguistic perception), and language (second language learning). The perception of languages refers to hearing and reading, while the creation of languages refers to speaking and writing. The four language skills are listening, reading, speaking, and writing. In particular, psycholinguistics helps to comprehend the difficulty of both intrinsic and extrinsic problems in these four skills. Psycholinguistics also contributes to explaining the language learning faults of students. In addition, psycholinguistics describes certain types of cerebral illnesses, such as graphics and aphasia, which must be treated appropriately, that influence language development. The use of the suitable approach for teaching these four linguistics teaches mainly psycholinguistic skills.
\end{abstract}

Keywords: cognitive process; language; learning; psycholinguistics; teaching

\section{INTRODUCTION}

The merging of psycholinguistics in two areas; psychology and linguistics. Linguistics the study of language, while psychology isthe mind and behavior study. Psycholinguistics can, therefore, generally be characterised as the study of mind and language. The relationship between the human mind and language is concerned when it analyses the procedures that take place in the brain during language production and perception.

Language production, language perception, and language acquisition encompass three key areas of psycholinguistics (Rączaszek-Leonardi\& Kelso,2008). The production of languages refers to the processes involved in language creation and expression. The perception of language refers to processes involved in both written and spoken language interpretation and understanding. Language acquisition refers to the acquisition of a mother tongue or a second language. There have been several

North South University, Dhaka, Bangladesh

*) corresponding author

Manna Dey

Email: deymanna113@gmail.com theories of psycholinguistics that explain the previous three points. In the subject of language education, theories were extremely useful. In designing language education approaches, several professionals adopt them as their fundamental theories. It is called a method of psycholinguistics. Psycholinguistic approach considers that language and thinking are connected phenomena but fully independent. Learning is seen as an individual cognitive process occurring within the person and subsequently progresses towards the social component (Acharya \& Relojo, 2017; Santos \& Relojo-Howell, 2020). Psycholinguistics is carried out in language teaching as research on the psychology of language. It helps to explore possible psychological elements in the learning of languages. Psycholinguistics focuses on the application and communication of the actual language. A decision must be made to use several approaches to make it easier for students to learn a language. There are certain approaches established based on ideas of psycholinguistics, and the methods are widely used in the language education sector throughout different countries (Relojo \& Pilao, 2018).

\section{Review of literatures}

Psycholinguistics is described simply as studying the connection between the language and the human mind (Lewis \& Phillips, 2015). In short, psycholinguistics explores three fundamental processes: (a) generation of languages, 
(b) language understanding, and (c) learning of language. In particular, two concerns that psycholinguistics seeks to respond address: (a) What language understanding is required for language use for us?and (b) Which procedures involve cognitive languages in their usual use?

As mentioned in Chaer (2015), psychology has swiftly developed and extended into various sub-disciplines: (a) Psycholinguistics of theory. It concentrated on language theories related to human linguistic processes, such as phonetics, dictionary, the design of syntaxes, speech, and intonation. (b) Psycholinguistics of development. It relates to language acquisition, both first language (L1) and second language (L2). It studies, progressively, integrated, process and phonological, semantic, and syntactic acquisition. (c) Social psycholinguistics, including social identity, relating to the social dimensions of language. (d) Psychology of education highlighted broad characteristics of school formal training such as language's involvement in teachinglearning skills and language skills to convey thoughts and feelings. (e) Neuropsycholinguistics focussed on language, language production, and human brain relationships. Neurologist professionals have been able to evaluate the biological structure of the brain and to analyse what is happening with the input language (Relojo, 2015). (f) Experimental psycholinguistics in all language productions and language work, language behavior, and language outcomes explored and experimented. (g) Applied psycholinguistics related to the application of the conclusions of six psycholinguistic subdisciplines discussed above in several fields, including psychology, linguistics, and the literature, language learning as well.

Psycholinguistic approach regards language and thinking as connected but fully autonomous (Berman, 2008). The psychological approach enables the individual cognitive internal processes to enable people to access the understandable input needed to make further progress when acquiring the L2 (Long, 1997). Krashen (1985) contends that learnersmust be exposed to a language input a little further than their existing degree of expertise to grasp and learn the language. Krashen outlines his opinion in his famous $\mathrm{i}+1$ notion that the input the learner receives should include, in addition to what he or she already knows, some small amounts of new knowledge. For Krashen, an understandable input is not only a necessary condition but also an adequate condition. Developmental psycholinguistics and applied psycholinguistics play an important role in developing successful methods of education in regard to language teaching. In accordance with men's physical and mental development, theoretical psycholinguistics covers the development of human language (Bautista et al., 2018). These theories are examined for second language learners to master the target language in the design of language training programmes and resources. Andika and Harras (2009) identify three types of ways of language education that are designed in accordance with principles of psycholinguistics: natural, physical response, and suggested contemporarymethods.

\section{Acquisition of language learning}

For people who are born (first acquiring language) and those learning a second or a foreign language, Field (2004) states that this word is utilised (second language acquisition). The use of the phrases remains unchallenged. Some specialists use the word 'language learning,' and some use the term 'language learning'Chaer (2015) explains the term 'language learning'as certain specialists feel that a second language can be mastered deliberately and deliberately by learning the language. This is different from a first language and language learned without a formal setting naturally and unconsciously. A phrase used to acquire the language is thought to be acquired formally or informally in the second or third language. The word employed in this research relates to the acquisition of second language learning. Language acquisition is of two types: naturalistic and formal. Previous investigations provide insight into how children extract, manipulate, and create the complex structures that exist within natural languages (Saffran et al., 2001)

\section{Language learning}

Language learning is the natural, conscious, and inadvertent learning of a language. In a bilingual or multilingual society, this generally happens. Formal language education with teachers, materials, and learning aids occurs in the classroom and other settings (Kuha et al., 2018; Pilao et al., 2019).Therefore, the phrase 'linguistic learning' is used in this study, which refers to the proceedings in the formal education of a person masters of a second or another language.Although employers acknowledge that most graduates are knowledgeable, they are also complaining that varsities are not producing quality output for them as most graduates lack soft skills (Pilao et al., 2017). This preliminary study was conducted to find out to what extent project-based learning ( $\mathrm{PjBL}$ ) facilitates the transference and inculcation of workplace-related skills. These skills are integrated in a project work assigned in the Workplace Communication course. This study will help the researchers to gauge students' learning experiences while undergoing the different processes involved in the project work. A set of questionnaires wasdesigned and administered to identify students' skills utilized in projectbased learning, namely language skills, interpersonal skills, critical thinking, collaborative skills, and leadership skills. Hence, this pilot study on project-based learning will assist the course designers in improving the project work instruction (Musa et al., 2011).

\section{Factors that influence language learning}

Some students learn a new language faster and easier than others. This fact was related to the key success criteria that are generally beyond student control. Lightbown and Spada (1990) reportedthat various elements influencing language learning had been identified. Smartness: Traditionally, 'smart' is used to refer to performance in particular types of tests. These assessments are often linked to school accomplishment, and sometimes a correlation was identified between intellectuals and second-language learning. Workout. Under the term of language learning' skill,' specific capacities to predict the success of language acquisition have been explored. Research has characterised the ability to learn swiftly.

Thus, we can expect that a highly skilled person can learn more efficiently and more quickly, but other students can also succeed when they continue. Style of study. The word 'lesson plan' was used to define the natural, customary and preferred approach for a person to absorb, process, and preserve information and skills. Some people believe they couldn't learn until they saw it. Such students would be part of a 'visual' group. Other folks, who might be known as aural students, seem to be learning the best by ear. A physical action such as miming or role play seems to contribute to the learning process for those known as 'kinaesthetic' learners. These are referred to as styles of perception. Characteristics: A variety of factors of personality that can affect second language learning have 
been presented. An outgoing person is generally believed to be well adapted for language learning. Inhibition is another feature of personality researched. Inhibition was recommended to prevent the taking of risks, which are important to advance language learning. In addition, student fears of concern, anxiousness, and tension have been widely examined by numerous students while learning a second language. A recent study into secondlanguage student anxiety recognises that anxiety is more likely to be dynamic and depend upon certain scenarios and conditions. Various other traits have also been investigated, including self-esteem, empathy, dominance, speech, and receptivity.

However, the effect of personality in language learning has not proven straightforward to demonstrate empirically. Intrinsic dictation: Two elements characterised the motivation: the communication demands of the learners and their attitudes about the second language. If students must speak the second language or meet professional objectives in a broad range of social circumstances, they will recognise the communicative worth of the second language and so be encouraged to acquire the skill. Likewise, students will want more to learn if they have a favourable attitude to the language speakers, especially within university settings (Relojo-Howell, 2019). Extrinsic dictation: Teachers also impact the conduct and motivation of students in language study. The teacher is one cause for students to study their second language or to have positive linguistic attitudes. The motivation of learners can contribute positively to teaching if classrooms are places where the students are happy because their content is interesting and relevant for their age and level of skill, the learning objectives are difficult but clear and manageable, as well as supporting the atmosphere (Ogwuche et al., 2020). Status of culture: Some research shows that pupils improve less quickly in situations where their own culture is lower than their own culture. More broad social issues can influence motivation, attitude, and the success of language learning. The social dynamics or the power of languages is one of those factors. Age: Second language study is influenced by the learner's age. Children with already strong knowledge of their original language seem best to acquire an effective new language. Motivated older students can also be highly effective, but they frequently struggle to reach natural speech and intonation. Researchhas shown that children and adults are distinguished from second language learning in specific characteristics like phonology, morphology, and syntax.

\section{Mechanism and strategy}

The definition of these three concepts by Harmer (2001) is distinctive. The approach refers to the theory of the nature of language learning as a source of language teaching strategies and principles. An approach outlines how language is utilised, and its elements interconnect -a model of language skill. An approach describes how people learn the language and make statements on the criteria for successful language learning. The main achievement of an approach is a method. The originators of a technique have decided what sorts of activities, teachers' and students' roles, what type of content is helpful, and what style of organisation of syllabus is. As part of their normal cuisine, the methods contain many methods and techniques.

\section{Approach to psychological language}

No child can't learn an original language, and it is learned mostly before the age of 5. Children are not formally taught language, yet all achieve the same level of skill when schools start using their mother tongue. Therefore, the psycholinguistic approach encouraged the idea of an authentic identification of language acquisition and rewired by birth as both language acquisition and improvement are biological processes. To acquire a language involves knowledge, knowledge, and other language-related mechanisms. Students are regarded as persons who are constantly engaged in their everyday activities in the three areas of psychology: cognitive, emotional, and psychomotor. The ability to use receptive and productive (speaking and writing) language with three previous areas. The ability to read and read. Spoken forms have an interdependent relationship of memory, perception, thought, meaning, and emotion with the minds of human beings (Demirezen, 2004). Language learning as a cognitive and individual process is considered to be psycholinguistic approaches in language learning, as a learner (a) is exposed to understandable material; (b) both have possibilities to negotiate, and (c) receive negative feedback. Language acquisition systems tend to accept that a student must be exposed to input (Aspachs-Bracons et al., 2008).

The second language acquisition (SLA) theories can be grouped into linguistic, psychological, and sociocultural theories. Krashen's Monitor Model is an 'innatist' theory within the linguistic group. Part of this 'innatist' theory is thatKrashen's input theory is one of the most wellinvestigated input ideas (1985). This hypothesis states that if a learner is exposed to understandable inputs, they will acquire a language. Therefore, the input should be only one step beyond the current stage of language proficiency to enhance the possibility of understanding input. The hypothesis of interaction states that in addition to the input to which the learner is exposed, manipulation of such material by interaction provides the basis for language development. According to Long (1997), the comprehensibility of input is enhanced as learners interact to overcome communications breakdowns through various interactional modifications (understanding checks, confirmation checks, and explanation requests). The socalled interactionists who have developed their study agendas to look at how speakers change their speech patterns and interaction enable their interlocutors to engage in, understand, and maintain the flow of conversations. The approach to psychology focuses on what people know when they communicate and how they acquire that knowledge and how they use it. Grimshaw et al. (1994) say that the psychological theory's primary approach is how humans biologically learn a language and what transformation principles allow them to understand it. This means that language acquisition should take into account developmentally appropriate instruction. It has been hypothesised that there is a critical period for firstlanguage acquisition that extends into late childhood and possibly until puberty. The hypothesis is difficult to test directly because cases of linguistic deprivation during childhood are fortunately rare.

\section{The four language competencies and psycholinguistic approach}

Psycholinguistic theories explain the psychological processes that occur when a person generates and understands a language in the human brain. Language perception involves hearing and reading activities (Relojo et al., 2016), whereas speech and writing activities are part of language production. The four actions are referred to as the four linguistic abilities. Some advantages of language acquisition and teaching psychological ideas, as indicated by Demirezen, are given below (2004). To this end, language 
competencies refer to using English in the four inter-related skills: speaking, listening, reading, and writing. The use of collaborative learning is a type of instruction where learners are grouped to work on an assignment, project, or task. To become competent in a second language, learners need to use English in each of four modalities actively. Learning English is also challenging for second language learners. Sometimes, some students feel demotivated and scared to use English inside the classroom during class discussions and recitations.

Approach of psychological language and hearing skill. Psycholinguistics researchers have shown that inner and extrinsic challenges need to be overcome in teaching listening to obtain a highly skilled listening activity. Speed of speaking, uncertain word numbers, and prior understanding of the topic are intrinsic difficulties. The external difficulty refers to the interest, motivation, the objective of listening, and noise in the environment of students. Knowledge in psycholinguistics helps teachers lessen the problems they have inherently and extrinsically. Teachers can create a narrative with 100 words, including ten new vocabulary items known to children. The teacher is also aware of reading pace and environmental noise. In addition, teachers can improve the interest and motivation of students by creating an entertaining and convenient class.

Approach and understanding of psycholinguistics. Psycholinguistics approach uses a text-based technique to underline the understanding activity and the top-down processing to highlight that understanding is essentially the knowledge foundation of students. Bottom-up processing occurs when someone tries to understand the language through the consideration of particular meanings or grammatical qualities of the most fundamental units of the text. Top-down language processing occurs when someone uses background data to forecast the meaning of the language to which they will read. They form expectations of what they will read rather than depending first on the actual words and confirm or reject them as they read. The approach underlines that a text's understanding largely depends on students' prior knowledge. Psycholinguistics aims to alleviate the intrinsic problems of reading by stimulating pupils' enthusiasm in reading. Teachers must provide genuine and contextual reading materials since pupils may fail to recognize their relevance to the real world when they are not properly exposed to genuine materials.

Writing and psychological approach. Psychology allows kids to understand the errors in writing. It contributes clearly to spelling errors since it is not spelled as it sounds in English. There is a difficulty here since it is quite tough to store the wording and find it on demand. Psycholinguistics shows that there are written faults that have to be dealt appropriately. Psycholinguistics allows you to locate intriguing subjects. It reduces the level of written challenges. It helps to identify the nature and type of writing. The report describes the mechanical errors of punctuation and proposes some remedies. To this end, blogs can also be an excellent source to learn a language (Relojo, 2018).

Speaking skills and psycholinguistics approach. Psycholinguistic method can regulate the instructional field as a competence. She identified a number of problems in speaking, like the student-oriented problem. Psycholinguistics argues also that personalities, such as introvert and extrovert students, influence the language learning performance of students. Speaking flaws such as voice disorder, tongue disorder, and disarticulation are also produced by personality element psychological. Traumatic conditions like aphasia and autism are also present because of localised damage. Therapies and counseling for such problems are recommended. Through the research on the psychological approach, nearly all language learning difficulties have been addressed through various services (Pinto-Coelho \& Relojo, 2017). By taking into consideration the condition of the learner, teachers can use adequate approaches to teach speech ability and can identify fascinating subjects to be covered in a speech lesson.

\section{Psycholinguistic language teaching methods}

Psycholinguistics is an integration of two different disciplines, psychology and linguistics. The former is the study of mind and behavior, while the latter is the study of language. Thus, psycholinguistics can be defined as studying the human mind and language and examining the processes that occur in the brain while producing and perceiving language. Psycholinguistics has provided several theories that enlighten how a person acquires a language, perceives, and produces in spoken and written contexts. The theories have been used in language learning and teaching. An approach to language education comprises of linguistic theories and linguistic theories. Methods for language education are the realization of approaches to language teaching. If its essential notions are fully grasped, a method for language education can be understood. Basic theories in the development of strategies for language learning are split into two principal theories: language theory and language learning theory. In the development of the language teaching method, there are three basic theoretical views: structural theory, functional theory, and interactional theory. Structural theory considers the language a grammatical system: sentences, paragraphs, phrases, appendices, etc. Functional theory regards language as a means of communication from its function: information, emotion, conviction, and social. Interaction theory sees language in terms of interpersonal relationships and social transactions between society and individuals. In developing the language instruction approach, each position implies differently. In addition to language theory, the development of a language teaching technique is also founded on two key questions on language learning theory; (a) which cognitive process engaged in language learning and (b) what conditions are required to achieve a high-quality language learning activity. These two questions were answered clearly by psycholinguistics. Thus, the development of language instruction methods was widely adopted as a core theory. Some strategies created based on psycholinguistic approach are described as (Harras and Andika, 2009)

Method of nature. Tracy Terrel (1977) develops this strategy. This method proposes that language education reflects the natural process in which people acquire their mother tongue. This method rejects previous methods like the audio method. Psycholinguistic principles follow this strategy in language learning: (a) Language mastery depends on the natural learning of the language abilities in a natural setting; (b) Language learning is an endeavour to improve communication skills, the ability to understand the language of native speakers and language speakers without making mistakes that interfere with the meaning of the language; (c) Understanding is primary than manufacturing. (d) Five monitors theory is the model underlying this method. Natural technology established by the teacher demonstrates the consistency of this method. The teacher encourages pupils to do skills such as problem-solving, gambling, and humanistic affection. Problem-solving is intended to train learners to find the proper solution. Games are regarded as a crossroads but are aimed to develop the language ability of students. 
Method of total physical performance. This method has been developed by James Asher (1966), a psychologist at San Jose State College. This strategy is followed by psycholinguistic principles in language learning: (a) The involvement of the kinaesthetic sensory system in language learning improves linguistic competency considerably. This was because youngsters are told to move physically; (b) Instead of producing speech, understanding is primary. Before trying to talk, students are directed to understanding skills.

In connection with kinaesthetic theory, the relationship between physical motions and the verbal achievement of pupils is regarded to be favourable and constitutes acceptance (Gagani et al., 2016). It focuses on the creation and application in a given subject of the appropriate language learning strategy. This strategy calls for a spacious classroom. Ideally, 20-25 students attend the class. This can be used to teach kids or adults. Grammatical norms are supplied in compulsory phrases because all material is essentially delivered in urgent phrases. This method requires no dictionary because the meaning of words is expressed through physical activity. Students don't frequently given homework, as language learning takes place in the classroom together. Language learning takes place in two types, naturalistic and formal language learning. Formal language learning occurs at the school, and some students learn quickly and efficiently than other language learners. There are related factors that influence language learning, and these factors are often beyond the control of the students.

\section{Suggested topics and future directions}

As Purva (2018) reported, Georgy Lazanov, a psychiatrist in Bulgaria, created this approach in 1975. This strategy is used to follow psycholinguistic principles in linguistic learning: (a) People can do something by giving them a comfortable and open, tranquil setting. This stimulates nerves to react easily and keep the information longer; (b) Students are convinced, before the session starts, to relax their mind and body in order to accumulate hypermnesic abilities; (c) The classroom has soft light, comfy sitting areas, relaxation, and classical music; (d) The laboratory programme is refused and the class is strictly grammatical exercised; and (e) In a long dialogue, the material is generally delivered. Each meeting is separated into three different assignments in this technique. The first one is a talk, games, sketch, or role-play to discuss the preceding topic. If students make certain mistakes, the teacher carefully corrects them to maintain a pleasant attitude. The second is the conventional distribution of the discussion. Thirdly, students are relaxed. This is separated into two: active and passive.

\section{Acknowledgments}

I would like to give a big thanks to my Lord and then my friends and teachers for their support and field contribution in this study.

\section{Declaration of Interest Statement}

The author declared no potential conflicts of interest with respect to the research, authorship, and/or publication of this article.

\section{REFERENCES}

Acharya, S. \& Relojo, D. (2017). Examining the role of cognitive distortion and parental bonding in depressive symptoms among male adolescents: A randomised crossover trial. Journal of Innovation in Psychology, Education and Didactics, 21(1), 7-20. $\underline{\text { https://doi.org/d9m6 }}$

Andika, D. B., \& Harras, K. A. (2009). Dasar-dasar psikolinguistik [Psycholinguistics market fundamentals]. Universitas Pendidikan Indonesia Press.

Asher, J. J. (1966). The Learning Strategy of the Total Physical Response: A review. The Modern Language Journal, 502), 79-84.https://doi.org/10.2307/323182

Aspachs-Bracons, O., Clots-Figueras, I., Costa-Font, J., \& Masella, P. (2008). Compulsory language educational policies and identity formation. Journal of the European Economic Association, 6(2-3), 434 444.https://doi.org/10.1162/jeea.2008.6.2-3.434

Bautista, L., Relojo, D., Pilao, S.J., Tubon, G., \& Andal, M. (2018). Link between lifestyle and self-regulated development as components of academic performance: Basis for a psychoeducational intervention. Journal on Educational Sciences \& Psychology, 8(52), 68-72. https://doi.org/f8nb

Berman, R. A. (2008). The psycholinguistics of developing text construction. Journal of child Language, 35(4), 735771. https://doi.org/10.1017/s0305000908008787

Chaer, A. (2015). Psikolinguistik: Kajian teorr[Psycholinguistics: Theoretical studies].PT Rineka Cipta.

Demirezen, M. (2004). Relations between psycholinguistic approach and foreign language learning and teaching. Ondokuz Mays Üniversitesi Eğitim Fakültesi Dergisi[Journal of Ondokuz Mays University Faculty of Education], 17, 26-36.

Gagani, A., Gemao, J., Relojo, D., Pilao, S.J. (2016). The stages of denial and acceptance among patients with chronic kidney disease. Journal on Innovation in Psychology, Education and Didactics, 20(2), 113-114. https://doi.org/gbzq

Grimshaw, G. M., Adelstein, A., Bryden, M. P., \& MacKinnon, G. E. (1998). First-language acquisition in adolescence: Evidence for a critical period for verbal language development. Brain and Language, 63(2), 237255.https://doi.org/10.1006/brln.1997.1943

Krashen, S.D. (1985). The input hypothesis: Issues and implications.Longman.

Kuha, A., Keawkubthong, H., \& Relojo, D. (2018). The development of professionalcompetency of teachers in Thailand: Meanings and implications. Psychreg Journal of Psychology, 2(2), 96-104. https://doi.org/f8nj

Lewis, S., \& Phillips, C. (2015). Aligning grammatical theories and language processing models. Journal of Psycholinguistic Research, 44(1), 27-46. https://doi.org/10.1007/s10936-014-9329-z

Lightbown, P. M., \& Spada, N. (1990). Focus-on-form and corrective feedback in communicative language teaching: Effects on second language learning. Studies in Second Language Acquisition, 12(4), 429448.https://doi.org/10.1017/s0272263100009517

Long, M. H. (1997). Construct validity in SLA Research: A response to Firth and Wagner. The Modern Language Journal, 81(3), 318-323.https://doi.org/10.1111/j.15404781.1997.tb05487.x 
Ogwuche, C.H., Caleb, O., \& Relojo-Howell, D. (2020). Perceived stress and social support as predictors of subjective well-being among university students in Nigeria. Psychology \& Society, 1(79), 120-125. https://doi.org/10.35774/pis2020.01.120

Pilao, S.J., Villanueva, A., Gornez, G.R., Villanueva, J.M., \& Relojo, D. (2017). Exploring wellness and quality of life among the elderly as a basis for a nursing care plan and psychosocial intervention. i-manager's Journal on Nursing, 73), 8-15. https://doi.org/f83x

Pilao, S.J., Dela Cruz, M.D., \& Relojo-Howell, D. (2019). The organisational learning of manpower service cooperative as basis for organisational development plan. CPQ Neurology and Psychology, 1(5), 1-7. https://doi.org/gkwf

Pinto-Coelho, A. \& Relojo, D. (2017). Overview of utilisation of mental health services in Portugal. Journal of Innovation in Psychology, Education and Didactics, 21(1), 57-68. https://doi.org/fkht

Purba, N. (2018). The role of psycholinguistics in language learning and teaching. Tell Journal, 6(1), 47. https://doi.org/10.30651/tell.v6i1.2077

Relojo, D. (2015). On the road to therapeutics: Biological mechanisms of Parkinson's disease and Alzheimer's disease. i-manager's Journal on Nursing, 5(3), 1-8. https://doi.org/gkwg

Relojo, D. (2018). The role of blog psychology in online mental health movement: Current status and implications. Problems of Psychology in the 21st Century, 12(1), 4-7. https://doi.org/10.33225/10.33225/ppc/18.12.04

Rączaszek-Leonardi, J., \& Kelso, J. S. (2008). Reconciling symbolic and dynamic aspects of language: Toward a dynamic psycholinguistics. New Ideas in Psychology, 26(2), 193207.https://doi.org/10.1016/j.newideapsych.2007.07.00 $\underline{3}$

Saffran, J. R., Senghas, A., \& Trueswell, J. C. (2001). The acquisition of language by children. Proceedings of the National Academy of Sciences, 98(23), 12874 12875.https://doi.org/10.1073/pnas.231498898

Santos, A. \& Relojo-Howell, D. (2020). Lifestyle and cognitive functioning of Filipino older adults as basis for cognitive enhancement programme. Psychology \& Society, 4(82), 97-105. https://doi.org/10.35774/pis2020.04.097

Terrell, T. D. (1977). A natural approach to second language acquisition and learning. The Modern Language Journal, 61(7), 325-337.https://doi.org/10.2307/324551 